\title{
Characteristics for Improvement of Compressive Strength of Geopolymers Made of Mixed Binders
}

\author{
Tatsuya Koumoto*
}

\author{
Prof. Emeritus of Saga University, Saga, Japan
}

\begin{abstract}
Geopolymers are composite hard materials made by mixing binders, such as fly ash and slags, and activators, such as $\mathrm{NaOH}$ and sodium silicate. The chemical mechanism for hardening composite materials, aluminosilicate binders, with alkaline activators is known as a geopolymer reaction. Geopolymers have recently been developed to be used as a replacement for Portland cement concrete. Industrial by-products such as fly ash, steel making slags, and garbage melting furnace slags can be made into geopolymers in a process that emits less carbon dioxide than in the cement making process. This reduction in $\mathrm{CO}_{2}$ emission is important because $\mathrm{CO}_{2}$ is one of the substances known to contribute to global warming. In the future, further uses of these fly ash and slags must be explored. The development of high compressive strength geopolymers using fly ash and slags will strongly contribute to the fields of construction, geotechnical engineering, and architecture.

So far, ground blast furnace slag has yielded the highest compressive strength geopolymer among various kind of binders such as fly ash, ground stainless steel-making slag, and garbage melting furnace slags. A potential use for the poor binders, yielding low compressive strength geopolymers, is to combine it with a richer binder to create stronger products. This paper examines the characteristics for improvement of compressive strength of geopolymers for the binders in various mixture ratios of poor binders and the ground blast furnace slag.
\end{abstract}

Keywords: Binder, Chemical composition, Compressive strength, Geopolymer, Strength Improvement characteristic.

\section{INTRODUCTION}

More than 60 million ton of industrial by-products such as fly ash, steel slags and garbage melting furnace slags are generated every year in Japan [1]. Geopolymers are composite hard materials made by mixing binders, such as fly ash and slags, and activators, such as $\mathrm{NaOH}$ and sodium silicate [2]. The chemical mechanism for hardening composite materials, aluminosilicate binders, with alkaline activators is known as a geopolymer reaction [3]. Geopolymers have recently been developed to be used as a replacement for Portland cement concrete. Industrial by-products such as fly ash, steel making slags, and garbage melting furnace slags can be used to create geopolymers in a process that emits less carbon dioxide than in the cement making process. This reduction in $\mathrm{CO}_{2}$ emission is important because $\mathrm{CO}_{2}$ is one of the substances known to contribute to global warming. In the future, further uses of these fly ash and slags must be explored. The development of high compressive strength geopolymer using fly ash and slags will strongly contribute to the fields of construction, geotechnical engineering, and architecture.

Koumoto [1] has found the ground blast furnace slag to be the binder that yielded the highest

*Address correspondence to this author at the Prof. Emeritus of Saga University, Saga, Japan; Tel/Fax: 0952-30-5868; E-mail: koumotot@gmail.com compressive strength geopolymer among various kind of binders such as fly ash, ground stainless steelmaking slag, and garbage melting furnace slags. Poor binders, yielding low compressive strength geopolymers can be effectively strengthened by combining with a richer binder, such as ground blast furnace slags. In this research the characteristics for improvement of compressive strength of geopolymers for binders in various mixture ratios of poor binders and the ground blast furnace slag are examined.

\section{MATERIALS}

\subsection{Preparation of Binders}

To examine the characteristics for improvement of compressive strength of geopolymer made of mixed binders, four cases of mixed binders: a. Reihoku+Koro, b. Karita+Koro, c. Stainless+Koro and d. Kazusa+Koro were prepared. Reihoku and Karita are fly ash, Stainless is ground stainless steel-making slag, Kazusa is garbage melting furnace, and Koro is ground blast furnace slag. In each case binders were mixed in various mixture ratio of $\delta$ which is defined by the following equation as:

$\delta=b 2 /(b 1+b 2)$

where b1: binder1 and b2: binder2.

The main chemical compositions of the mixed binders tested are listed in Table 1. In Table 1, 
Table 1: Chemical Compositions of Tested Binders

\begin{tabular}{|c|c|c|c|c|c|c|c|c|}
\hline \multirow[t]{2}{*}{ Binders } & \multirow{2}{*}{$\begin{array}{l}\text { Name of } \\
\text { samples }\end{array}$} & \multirow{2}{*}{$\begin{array}{c}\text { Mixture ratio } \\
\delta==b 2 /(\mathrm{b} 1+b 2) \\
\end{array}$} & \multicolumn{6}{|c|}{ Chemical composition (\%) } \\
\hline & & & $\mathrm{SiO}_{2}$ & $\mathrm{Al}_{2} \mathrm{O}_{3}$ & $\mathrm{CaO}$ & $\mathrm{Fe}_{2} \mathrm{O}_{3}$ & MgO & $\mathrm{SO}_{3}$ \\
\hline \multirow{4}{*}{$\begin{array}{c}\text { Reihoku+Koro } \\
\text { b1=Reihoku } \\
\text { b2=Koro }\end{array}$} & Reihoku* & 0.00 & 55.0 & 21.1 & 9.1 & 5.3 & 1.1 & 0.9 \\
\hline & KoroRei5 & 0.17 & 51.6 & 20.1 & 14.7 & 4.5 & 1.9 & 0.8 \\
\hline & ReiKoro* & 0.50 & 44.8 & 18.0 & 25.9 & 2.9 & 3.4 & 0.5 \\
\hline & ReiKoro2* & 0.67 & 41.4 & 16.9 & 31.5 & 2.0 & 4.2 & 0.3 \\
\hline \multirow{4}{*}{$\begin{array}{c}\text { Karita+Koro } \\
\text { b1=Karita } \\
\text { b2=Koro }\end{array}$} & KoroKari5 & 0.17 & 38.1 & 22.7 & 23.4 & 1.4 & 1.4 & 5.5 \\
\hline & KariKoro* & 0.50 & 36.7 & 19.5 & 31.1 & 1.0 & 3.1 & 3.3 \\
\hline & KariKoro2* & 0.67 & 36.0 & 18.0 & 35.0 & 0.8 & 4.0 & 2.2 \\
\hline & KariKoro5 & 0.83 & 35.3 & 16.4 & 38.8 & 0.6 & 4.8 & 1.1 \\
\hline \multirow{3}{*}{$\begin{array}{c}\text { Stainless+Koro } \\
\text { b1=Stainless } \\
\text { b2=Koro }\end{array}$} & KoroSta2 & 0.33 & 29.4 & 8.5 & 46.3 & 0.8 & 5.5 & 0.3 \\
\hline & StaKoro & 0.50 & 30.7 & 10.1 & 45.4 & 0.7 & 5.6 & 0.2 \\
\hline & StaKoro2 & 0.67 & 32.0 & 11.6 & 44.5 & 0.8 & 5.6 & 0.1 \\
\hline \multirow{5}{*}{$\begin{array}{c}\text { Kazusa+Koro } \\
\text { b1=Kazusa } \\
\text { b2=Koro }\end{array}$} & Kazusa* & 0.00 & 34.2 & 13.2 & 42.0 & 2.6 & 1.9 & 0.7 \\
\hline & KoroKazu3 & 0.25 & 34.3 & 13.7 & 42.2 & 1.9 & 3.2 & 0.5 \\
\hline & KazuKoro* & 0.50 & 34.4 & 14.0 & 42.4 & 1.5 & 3.8 & 0.4 \\
\hline & KazuKoro2* & 0.67 & 34.5 & 14.3 & 42.5 & 1.1 & 4.4 & 0.2 \\
\hline & KazuKoro5 & 0.83 & 34.5 & 14.5 & 42.6 & 0.8 & 5.1 & 0.1 \\
\hline b1=0, b2=Koro & Koro* & 1.00 & 34.6 & 14.8 & 42.7 & 0.4 & 5.7 & 0.0 \\
\hline
\end{tabular}

Note: Reihoku and Karaita= Fly ash; Koro= ground blast furnace slag; Stainless= ground stainless steel-making slag; Kazusa= ground garbage melting furnace slag *: data from Koumoto [1].

Reihoku, Karita, Stainless, and Kazusa $=$ binder1 (poor binder) and Koro = binder2 (richer binder).

Figure 1 shows a triangular coordinate display for chemical compositions of binders listed in Table 1. In Figure 1a triangle is drawn for $\mathrm{CaO}, \mathrm{SiO}_{2}$ and $\mathrm{Al}_{2} \mathrm{O}_{3}+$ others. This display method helps us to understand the situation of chemical compositions of mixed binders according to the mixture.

\subsection{Making of Geopolymer Samples}

Although there are several kinds of liquid sodium hydroxide and sodium silicate as activators, in this research both $48 \% \mathrm{NaOH}(18 \mathrm{~mol} / \mathrm{L})$ and Sodium silicate $\left(\mathrm{Na}_{2} . n \mathrm{SiO}_{2}, n=3.2\right)$ which are commercial and expected to yield the high compressive strength geopolymers because of their high concentration, are used. The compressive strengths of geopolymers $q_{u}$ is generally considered as a function of $\mathrm{w}$ ( $=$ weight ratio of activator to binder) and $\eta$ (= weight ratio of $\mathrm{NaOH}$ to Sodium silicate). In this research, according to
Koumoto [1], the $w_{\text {opt }}$, which is the optimum value of $w$ yielding the ultimate compressive strength $q_{u m a x}$, becomes a constant value of $w=0.4$. Geopolymer samples were made for variable $\eta$ value with a value of $w=0.4$. The geopolymer samples were filled up after mixing the activator and binder in the plastic molds of diameter $\varphi=50 \mathrm{~mm} \times$ height $\mathrm{h}=100 \mathrm{~mm}$ with slight vibration. The geopolymer samples were removed from the mold after one or two days and cured at room temperature under the dried condition for 28 days.

\section{TEST AND RESULTS}

\subsection{Compression Tests}

Before compression test, physical properties of geopolymer samples such as diameter (d), height (h), and weight (W) were measured to obtain characteristics of shrinkage and density. Compression tests of geopolymer samples were carried out at the Saga Construction Technology Support Organization (SCTSO) using the concrete testing apparatus in the 


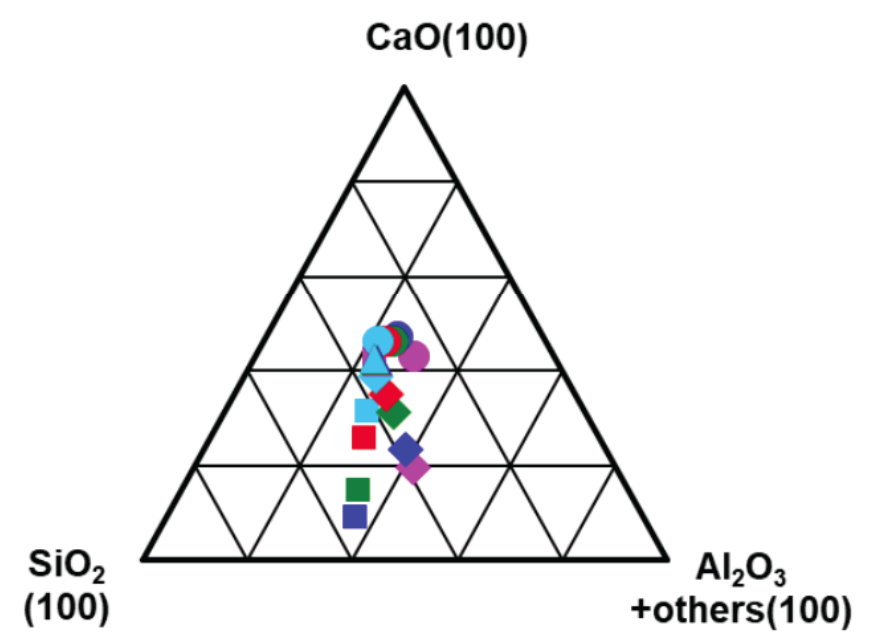

\begin{tabular}{|r|r|r|c|}
\hline CaO & SiO2 & marker & sample \\
\hline 42.7 & 34.6 & & Koro \\
\hline 9.1 & 55.0 & & Reihoku \\
\hline 14.7 & 51.6 & & KoroRei5 \\
\hline 25.9 & 44.8 & & ReiKoro \\
\hline 31.5 & 41.4 & & ReiKoro2 \\
\hline 19.5 & 38.8 & & Karita \\
\hline 23.4 & 38.1 & & KoroKari5 \\
\hline 31.1 & 36.7 & & KariKoro \\
\hline 35.0 & 36.0 & & KariKoro2 \\
\hline 38.8 & 36.3 & & KariKoro5 \\
\hline 43.2 & 26.7 & & Stainless \\
\hline 47.3 & 28.0 & & KoroSta5 \\
\hline 46.3 & 29.4 & & KoroSta2 \\
\hline 46.4 & 30.7 & & StaKoro \\
\hline 46.5 & 32.0 & & StaKoro2 \\
\hline 42.0 & 34.2 & $\Delta$ & Kazusa \\
\hline 42.2 & 34.3 & $\Delta$ & KoroKazu3 \\
\hline 42.4 & 34.4 & $\Delta$ & KazuKoro \\
\hline 42.5 & 34.5 & $\Delta$ & KazuKoro2 \\
\hline 42.6 & 34.5 & $\Delta$ & KazuKoro5 \\
\hline & & & \\
\hline
\end{tabular}

Figure 1: Triangular coordinate display for chemical compositions of binders of geopolymer samples.

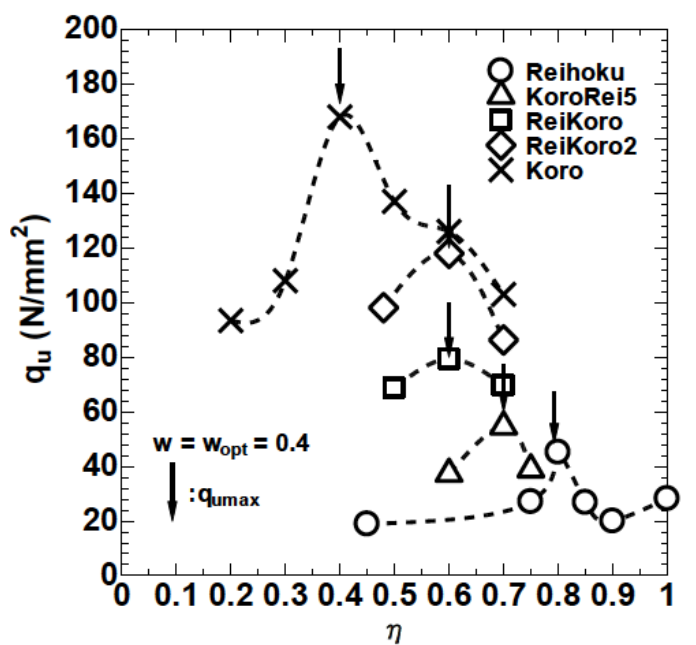

a

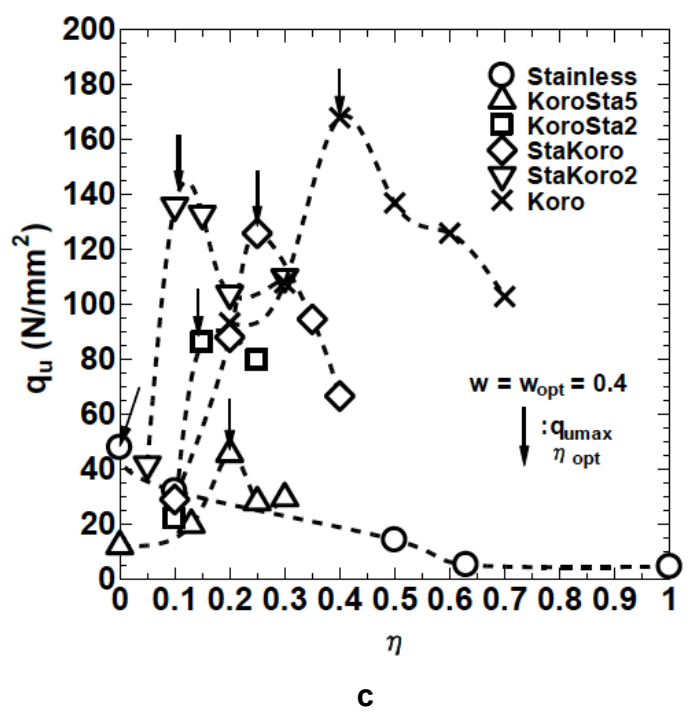

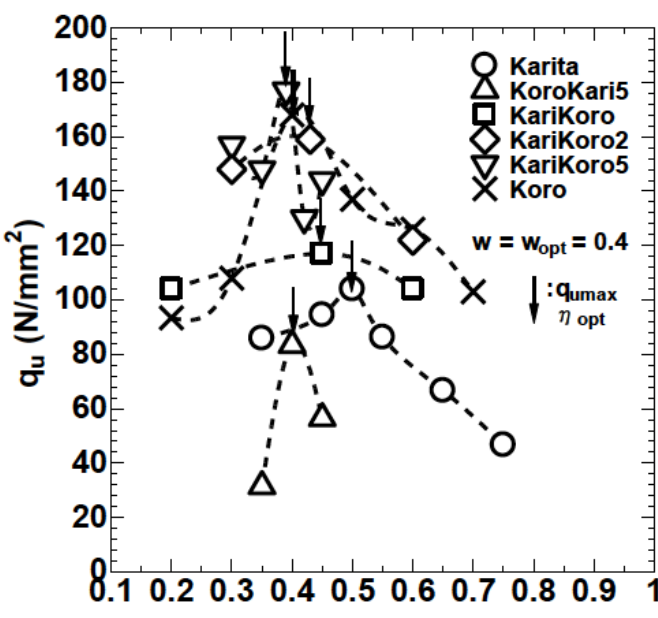

b

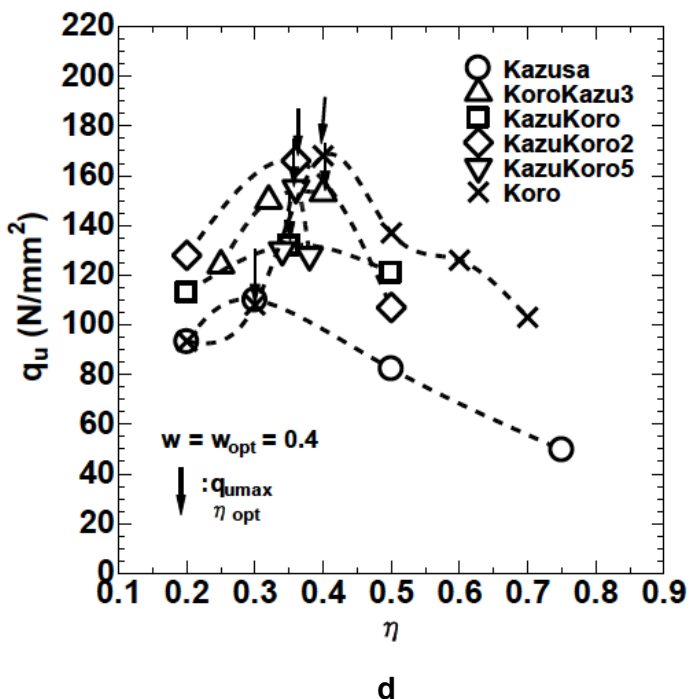

Figure 2: Compression test results for geopolymers: (a) Reihoku+Koro; (b) Karita+Koro; (c) Stainless+Koro; (d) Kazusa+Koro. 
Table 2: Compression Test Results of Geopolymer Samples

\begin{tabular}{|c|c|c|c|c|c|c|c|}
\hline Binders & $\begin{array}{l}\text { Name of } \\
\text { samples }\end{array}$ & $\begin{array}{l}\text { Mixture ratio } \\
\delta=b 2 /(b 1+b 2)\end{array}$ & \multicolumn{5}{|c|}{ Compression test results } \\
\hline \multirow{4}{*}{$\begin{array}{c}\text { Reihoku+Koro } \\
\text { b1=Reihoku } \\
\text { b2=Koro }\end{array}$} & Reihoku* & 0.00 & 45.2 & 0.40 & 0.80 & 1,868 & 0.20 \\
\hline & KoroRei5 & 0.17 & 54.6 & 0.40 & 0.70 & 2,016 & 1.99 \\
\hline & ReiKoro* & 0.50 & 79.3 & 0.40 & 0.60 & 2,098 & 0.70 \\
\hline & ReiKoro2* & 0.67 & 118.0 & 0.40 & 0.60 & 2,144 & 1.20 \\
\hline \multirow{4}{*}{$\begin{array}{c}\text { Karita+Koro } \\
\text { b1=Karita } \\
\text { b2=Koro }\end{array}$} & KoroKari5 & 0.17 & 83.4 & 0.40 & 0.40 & 2,144 & 0.50 \\
\hline & KariKoro* & 0.50 & 117.0 & 0.40 & 0.45 & 2,122 & 0.90 \\
\hline & KariKoro2* $^{*}$ & 0.67 & 159.0 & 0.40 & 0.43 & 2,149 & 0.70 \\
\hline & KariKoro5 & 0.83 & 177.0 & 0.40 & 0.39 & 2,183 & 1.09 \\
\hline \multirow{2}{*}{$\begin{array}{c}\text { Stainless+Koro } \\
\text { b1=Stainless } \\
\text { b2=Koro }\end{array}$} & Stainless* & 0.00 & 48.1 & 0.40 & 0.00 & 2,269 & 11.34 \\
\hline & StaKoro2 & 0.67 & 136.0 & 0.40 & 0.10 & 2,261 & 2.68 \\
\hline \multirow{5}{*}{$\begin{array}{c}\text { Kazusa+Koro } \\
\text { b1=Kazusa } \\
\text { b2=Koro }\end{array}$} & Kazusa* & 0.00 & 110.0 & 0.40 & 0.30 & 2,202 & 1.49 \\
\hline & KoroKazu3 & 0.25 & 153.0 & 0.40 & 0.40 & 2,183 & 2.08 \\
\hline & KazuKoro* & 0.50 & 132.0 & 0.40 & 0.35 & 2,219 & 1.29 \\
\hline & KazuKoro2* & 0.67 & 166.0 & 0.40 & 0.36 & 2,218 & 1.49 \\
\hline & KazuKoro5 & 0.83 & 155.0 & 0.40 & 0.36 & 2,349 & 1.49 \\
\hline b1=0, b2=Koro & Koro* & 1.00 & 168.0 & 0.40 & 0.40 & 2,227 & 1.20 \\
\hline
\end{tabular}

Note: $q_{u m a x}=$ maximum value of compressive strength $q_{u} ; w_{o p t}=$ optimum value of $w$ yielding $q_{u m a x} ; \eta_{\text {opt }}=$ optimum value of $\eta$ yielding $q_{u m a x} ; \rho_{t}=$ density $_{\text {of }}$ geopolymer sample yielded qumax; $\Delta \mathrm{V} / \mathrm{V}=$ volume shrinkage ratio of geopolymer sample yielded qumax.

*: data from Koumoto [1].

same test method for concrete samples (sample diameter $\mathrm{d}=50 \mathrm{~mm}$ and height $\mathrm{h}=100 \mathrm{~mm}$, loading rate $=0.6 \pm 0.4 \mathrm{~N} / \mathrm{mm}^{2}$ and loading plate $\varphi=300 \mathrm{~mm}$ ).

\subsection{Test Results}

Compression test results are shown in Figure $\mathbf{2 a}, \mathbf{b}$, c and $\mathbf{d}$ which show the relationship between the compressive strength $q_{u}$ and $\eta$ for $w=w_{\text {opt }}=0.4$. As shown in Figure $\mathbf{2 a}, \mathbf{b}, \mathbf{c}$ and $\mathbf{d}, \mathrm{q}_{\mathrm{u}}$ generally increases with an increase in $\eta$ and reach the maximum value $q_{u m a x}$ at a certain $\eta$ value, which is defined as the optimum value $\eta_{\text {opt }}$. The values of $q_{\text {umax }}$ and $\eta_{\text {opt }}$ from Figure 2a, b, $\mathbf{c}$ and $\mathbf{d}$ are summarized in Table 2. Table 2 also includes the value of $w_{\text {opt }}$ and both values of the density $\rho_{\mathrm{t}}$ and the volume shrinkage ratio $\Delta \mathrm{V} / \mathrm{V}$ of geopolymer sample yielded the $q_{\text {umax }}$.

\section{DISCUSSIONS}

\subsection{Relationship between $q_{u m a x}$ and Mixture Ratio of Binders $\delta$}

Figure $3 \mathbf{a}, \mathbf{b}, \mathbf{c}$ and $\mathbf{d}$ shows the relationship between qumax and $\delta$. From Figure $\mathbf{3 a}, \mathbf{b}, \mathbf{c}$ and $\mathbf{d}$ the $q_{\text {umax }}$ generally increases with an increase of $\delta$ along the broken straight line which is drawn between the $q_{\text {umax }}$ for binder1 and the one for binder2 (Koro). It is interesting that in the case of Figure 3c Karita+Koro, the value of $\mathrm{q}_{\mathrm{umax}}$ for $\delta=0.83$ becomes larger than that for $\delta=1$ ( Koro).

Figure 4 shows the relationship between $q_{u m a x}$ and $\mathrm{C}_{\text {cas }}\left(=\mathrm{CaO} /\left(\mathrm{Al}_{2} \mathrm{O}_{3}+\mathrm{SiO}_{2}\right)\right)$. From Figure 4 the $q_{\text {umax }}$ increases with an increase of the factor $\mathrm{C}_{\text {cas }}$ until $\mathrm{C}_{\text {cas }}$ becomes 0.75 , after that $q_{\text {umax }}$ decreases with an increase of $\mathrm{C}_{\text {cas }}$. The relationship of $\mathrm{q}_{\text {umax }}$ and $\mathrm{C}_{\text {cas }}$ seems to become a curve showing a peak at $\mathrm{C}_{\text {cas }}$ of 0.75 .

\subsection{Relationship between $\eta_{\mathrm{opt}}$ and $\delta$}

Figure 5 shows the relationship between $\eta_{\text {opt }}$ and $\delta$. From Figure 5 the $\eta_{\text {opt }}$ for each binder1 $(\delta=0)$ approaches to the $\eta_{\text {opt }}$ for Koro $(\delta=1)$ with an increase of $\delta$.

Figure 6 shows correlation between $\eta_{\text {opt }}$ and $C_{\text {cas }}$. The relationship between $\eta_{\text {opt }}$ and $C_{\text {cas }}$ is expressed by the following equation with a high correlation coefficient of $r=0.932$ as 


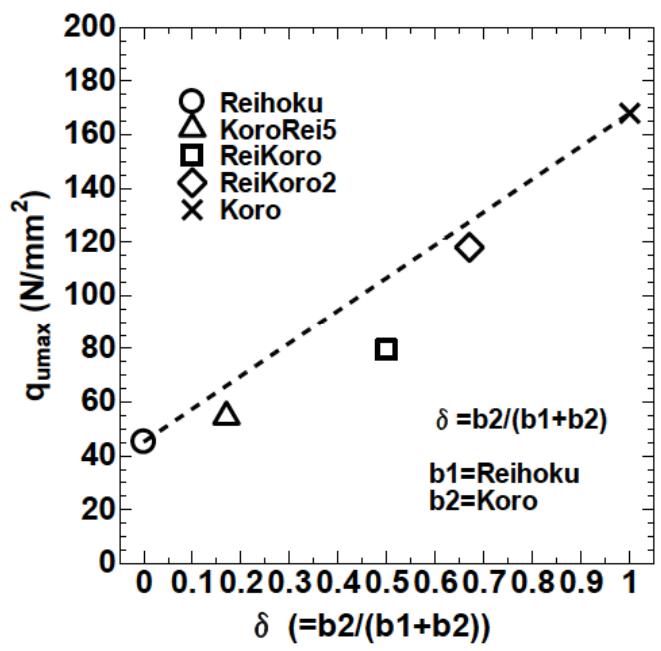

a

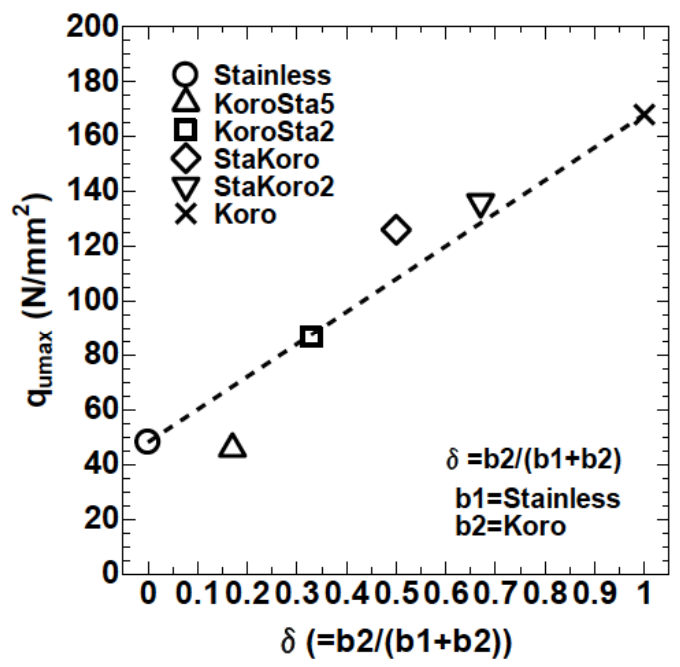

C

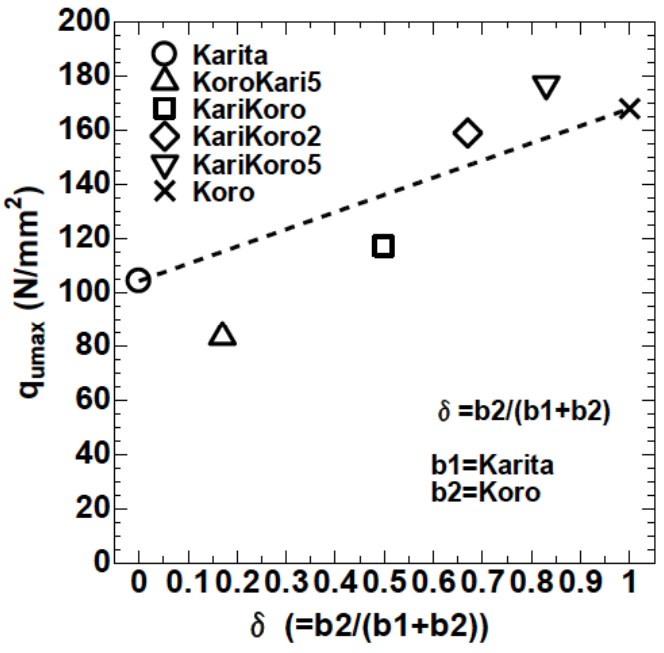

b

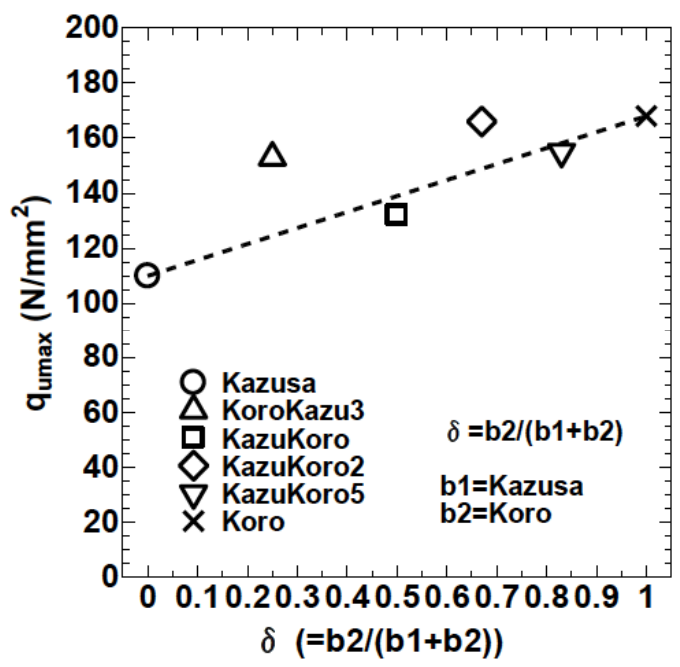

Figure 3: Relationship between qumax and $\delta$ : (a) Reihoku+Koro; (b) Karita+Koro; (c) Stainless+Koro; (d) Kazusa+Koro.

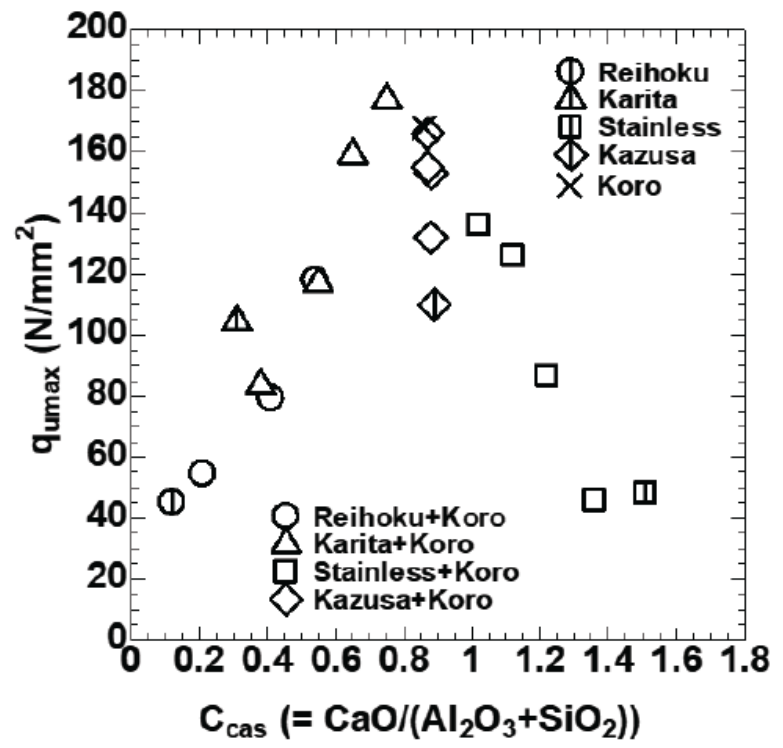

Figure 4: Relationship between $\mathrm{qumax}_{\text {and }} \mathrm{C}_{\text {cas }}$.

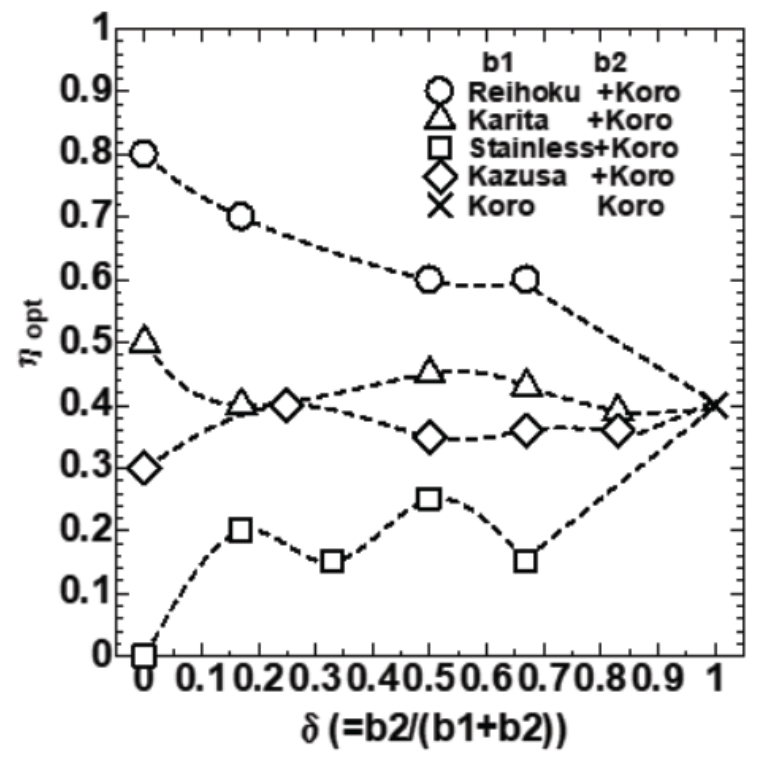

Figure 5: Relationship between $\eta_{\mathrm{opt}}$ and $\delta$. 
$\eta_{\mathrm{opt}}=0.842-0.580 \mathrm{C}_{\mathrm{cas}}{ }^{0.855}$

Eq. (2) is used to calculate the $\eta_{\text {opt }}$ value from the value of $\mathrm{C}_{\text {cas }}\left(=\mathrm{CaO} /\left(\mathrm{Al}_{2} \mathrm{O}_{3}+\mathrm{SiO}_{2}\right)\right)$ of binders to effectively produce high compressive strength geopolymers.

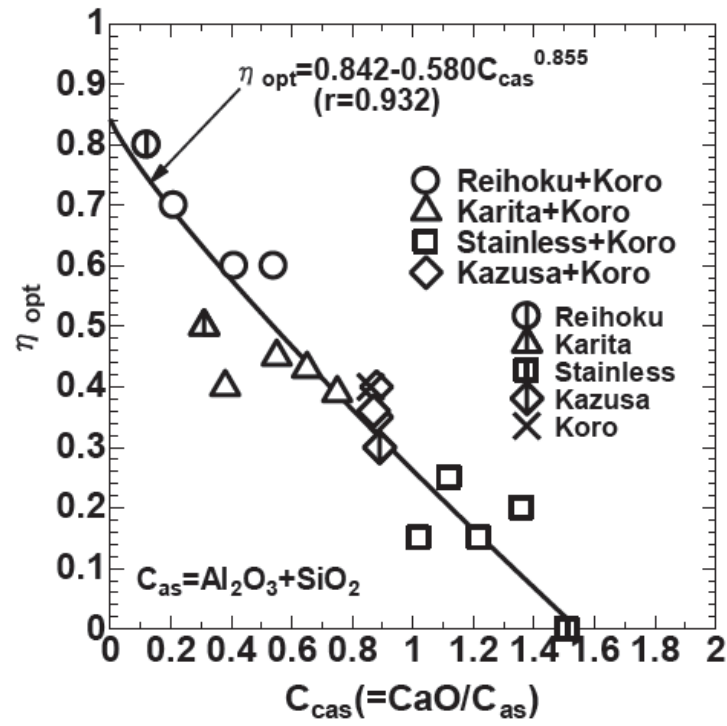

Figure 6: Correlation between $\eta_{\mathrm{opt}}$ and $\mathrm{C}_{\text {cas }}$.

\subsection{Relationship between $\Delta V / V$ and $\delta$}

Figure 7 shows the relationship between the volume shrinkage ratio for geopolymer sample yielded $\mathrm{q}_{\mathrm{umax}}$ $\Delta \mathrm{V} / \mathrm{V}$ and $\delta$. In Figure 7 the $\Delta \mathrm{V} / \mathrm{V}$ in the case of binder 1 Stainless is the largest among all binder1 (Reihoku, Karita, Stainless and Kazusa) and the $\Delta \mathrm{V} / \mathrm{V}$ in the cases of other binder1 are rather lower than $\Delta \mathrm{V} / \mathrm{V}=2$ $\%$. From Figure 7 the $\Delta \mathrm{V} / \mathrm{V}$ of Stainless is remarkably improved with an increase of $\delta$.

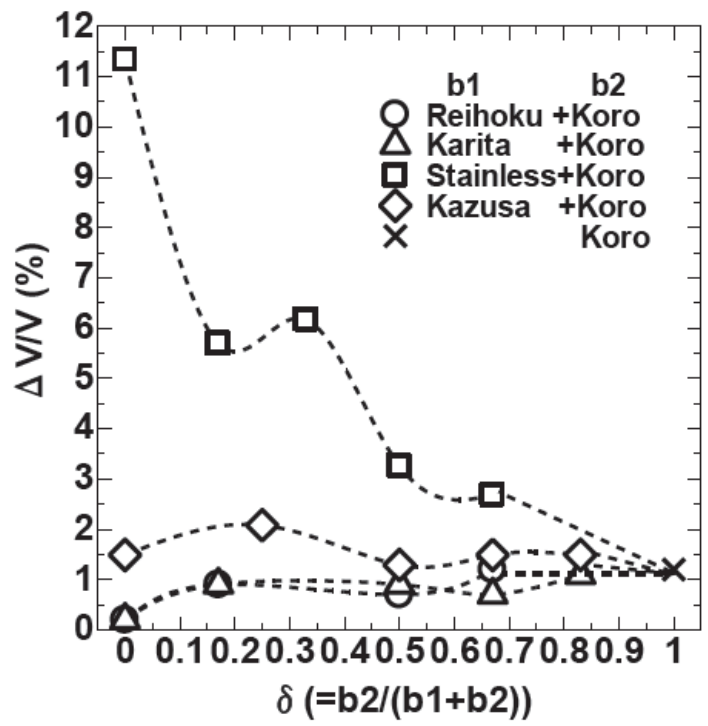

Figure 7: Relationship between $\Delta \mathrm{V} / \mathrm{V}$ and $\delta$.
Figure 8 shows the relationship between $\Delta \mathrm{V} / \mathrm{V}$ and $\mathrm{C}_{\text {cas. }}$. From Figure $\mathbf{8}$ generally the smaller the $\mathrm{C}_{\text {cas }}$ of the binder1 the smaller the $\Delta \mathrm{V} / \mathrm{V}$ of the geopolymer. It is said that mixing the stainless (binder1) with the Koro (binder2) remarkably improves the $\Delta \mathrm{V} / \mathrm{V}$ of the geopolymer of the Stainless.

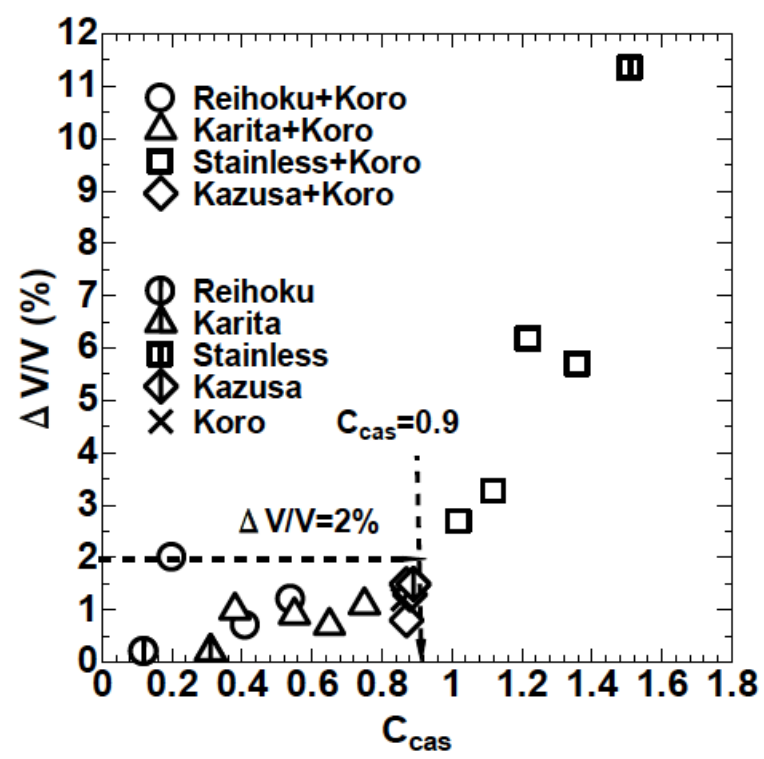

Figure 8: Relationship between $\Delta \mathrm{V} / \mathrm{V}$ and $\mathrm{C}_{\text {cas }}$.

\section{CONCLUSIONS}

In the research, the characteristics for improvement of compressive strength of geopolymers for the binders in various mixture ratios of poor binders and the ground blast furnace slag (Koro) are examined.

The research results are summarized as:

1. Triangular coordinate display method in which a triangle is drawn for $\mathrm{CaO}, \mathrm{SiO}_{2}$ and $\mathrm{Al}_{2} \mathrm{O}_{3}$ +others help us to understand the situation of chemical compositions of mixed binders according to the mixture.

2. The $q_{u m a x}$ generally increases with an increase of $\delta$ along the broken straight line which is drawn between the qumax for binder1 and the one for binder2 (Koro).

3. The $\eta_{\mathrm{opt}}$ for each binder1 $(\delta=0)$ approaches to the $\eta_{\text {opt }}$ for Koro $(\delta=1)$ with an increase of $\delta$.

4. The correlation between $\eta_{\text {opt }}$ and $\mathrm{C}_{\text {cas }}$ $\left(=\mathrm{CaO} /\left(\mathrm{Al}_{2} \mathrm{O}_{3}+\mathrm{SiO}_{2}\right)\right)$ is expressed by the following equation with a high correlation coefficient of $r=0.932$ as: 
$\eta_{\text {opt }}=0.842-0.580 \mathrm{C}_{\text {cas }}{ }^{0.855}$ in which $\mathrm{C}_{\text {cas }}=\mathrm{CaO} /\left(\mathrm{Al}_{2} \mathrm{O}_{3}\right.$ $+\mathrm{SiO}_{2}$ ).

This equation is used to calculate the $\eta_{\text {opt }}$ value from the value of $\mathrm{C}_{\text {cas }}$ of binders to effectively produce high compressive strength geopolymers.

5. In the case of binder1, Stainless is the largest $\Delta \mathrm{V} / \mathrm{V}$ among all binder1 (Reihoku, Karita, Stainless and Kazusa) and the $\Delta V / V$ in the cases of other binder1 are lower than $\Delta \mathrm{V} / \mathrm{V}=2 \%$.

In the case of Stainless the $\Delta \mathrm{V} / \mathrm{V}$ can be remarkably improved from $11 \%$ until $2 \%$ by mixing with the binder of Koro.

\section{REFERENCES}

[1] Koumoto T. Production of High Compressive Strength Geopolymers Considering Fly Ash or Slag Chemical Composition. J Mater Civ ASCE 2019; 31(18): 06019006. https://doi.org/10.1061/(ASCE)MT.1943-5533.0002788

[2] Davidovits J. Geopolymers inorganic polymeric new materials. J Therm Anal 1991; 37(8): 1633-1656. https://doi.org/10.1007/BF01912193

[3] Buchwald A. What are geopolymers? Current state of research and technology, the opportunities they offer, and their significance for precast industry. Betonwerk und Fertigteil-Technik 2006; 72(7): 42-49.

Received on 22-10-2020

Accepted on 19-11-2020

Published on 23-11-2020

DOI: https://doi.org/10.31875/2410-4701.2020.07.05

(C) 2020 Tatsuya Koumoto; Zeal Press

This is an open access article licensed under the terms of the Creative Commons Attribution Non-Commercial License (http://creativecommons.org/licenses/by-nc/3.0/) which permits unrestricted, non-commercial use, distribution and reproduction in any medium, provided the work is properly cited. 